\title{
TWEE ARMSTOELEN: HERKOMST ONBEKEND?
}

Van meubelen die in Europa zijn vervaardigd is het vaak niet makkelijk om de herkomst of de datering te bepalen. Voor meubelen die in de koloniale tijd voor Europeanen in Azië gemaakt zijn, is dit nog veel moeilijker. Archieven zijn vaak niet meer compleet of in het geheel niet overgeleverd. Veel Europeanen in Azië werden met regelmaat overgeplaatst of keerden weer terug naar Europa. In beide gevallen werd een groot deel van het huisraad verkocht. Een meubel kon op die manier in enkele decennia in vele handen overgaan. Archivalische informatie over de eigenaars biedt dus maar zelden houvast. Met het dateren op stilistische gronden van een koloniaal meubel uit de zeventiende of achttiende eeuw is voorzichtigheid geboden. Hoewel in de achttiende eeuw in Indië de Europese stijlontwikkelingen wel gevolgd werden, is er nog maar weinig bekend over de mate waarin en het tempo waarmee dit gebeurde.

Soms is het echter wel mogelijk om de herkomst van een koloniaal meubel te bepalen. Dergelijke meubels hebben een expliciete verwijzing naar de functie of de voormalige eigenaar. Een voorbeeld hiervan is te vinden in de zogenaamde 'Compagnieskamer' in het Museum Sejarah in Jakarta. Daar staat een boekenkast opgesteld waarvan zeker is dat deze rond 1748 gemaakt is voor de Raad van Justitie in Batavia. In de enorme kuif van dit deels vergulde meubel zijn de wapens gesneden van de president en de leden van de Raad. Op de hoeken zijn twee beelden aangebracht die de 'Gerechtigheid' en de 'Waarheid' symboliseren.'

\section{Een armstoel uit de Coromandelkust of Sri Lanka}

Ook als zulke expliciete aanwijzingen voor de datering en ontstaansgeschiedenis ontbreken, is het - door zoveel mogelijk informatie te combineren soms mogelijk tot een overtuigende toeschrijving van een meubel te komen. De afgebeelde armstoel uit de zeventiende eeuw valt op door zijn rijke uitvoering met inlegwerk van ivoor (afb. 1). Het gebruik van inlegwerk met ivoor komt veel voor langs de zuidoostkust van India (destijds de Coromandelkust genaamd) en in het huidige Sri Lanka, het vroegere Ceylon. Het zou daarom voor de hand liggen dat dit type meubelen in deze gebieden vervaardigd is, maar juist bij deze meubelen is dit niet met zekerheid te zeggen. Nadat Ceylon in 1658 in Nederlandse handen kwam, bracht de VOC veel Tamil-slaven naar de vestigingsplaatsen op Ceylon en Batavia. Een deel van deze slaven werkte onder andere in werkplaatsen onder toezicht van Europese ambachtslieden. ${ }^{2}$

Dat het meubel vervaardigd werd door een ambachtsman van de Coromandelkust of uit Sri Lanka is vrijwel zeker door de uitwerking van de florale motieven en vooral het gebruik van ivoor. Bovendien zijn verschillende

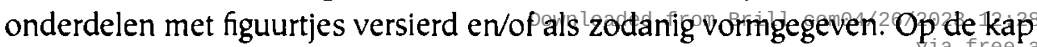

\footnotetext{
Afbeelding 1 


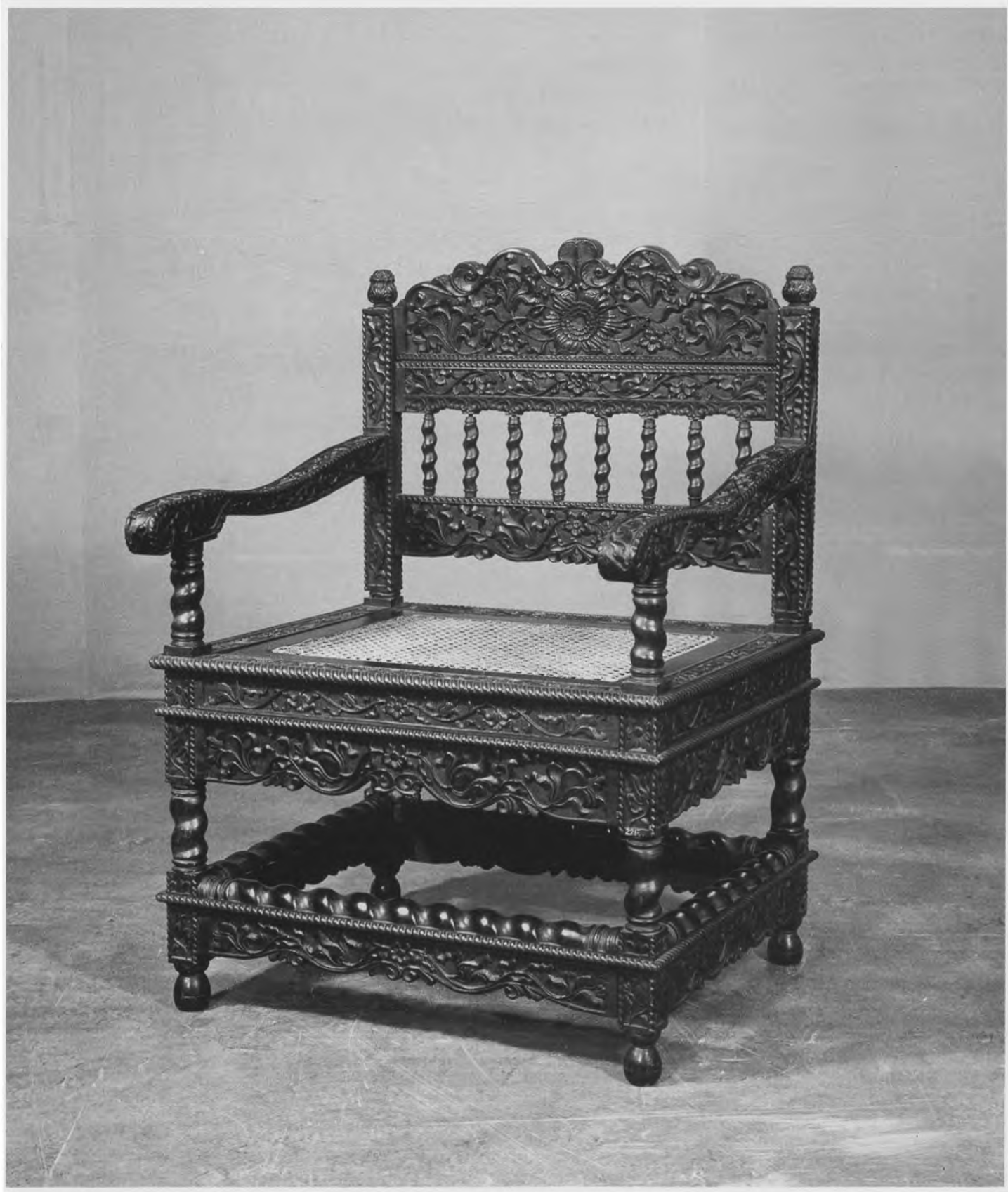

\section{Afbeelding 2}

Armstoel

h. $72 \mathrm{~cm}$.

Batavia, tweede helft 
van de rug en de onderregels zijn Nereïden te zien; op de rugstijlen zitten twee papegaaien en de armstutten hebben de vorm van een Hollandse soldaat.

Omdat de islam het afbeelden van mensen en dieren niet toestaat, zou dit erop kunnen wijzen dat dit type decoratie niet door ambachtslieden uit de Indische archipel zou zijn vervaardigd. De islam werd in de veertiende eeuw geïntroduceerd in de Indische archipel en kreeg vanaf die tijd steeds meer volgelingen. De islamisering van oude tradities verliep echter minder snel en zou pas echt doorzetten aan het einde van de negentiende eeuw. Het wayangspel bijvoorbeeld, dat menselijke figuren uitbeeldt, is door de komst van de islam niet verdwenen uit de Javaanse cultuur. Het is daarom niet waarschijnlijk dat afbeelden van menselijke figuren op veel weerstand zou stuiten en dus valt Indonesië als plaats van vervaardiging niet uit te sluiten. Het is overigens niet vreemd dat aan het begin van de twintigste eeuw werd geconcludeerd dat Javaanse ambachtslieden geen menselijke figuren wilden uitvoeren. Op de tentoonstelling naar aanleiding van het 300 -jarig bestaan van Batavia in 1919 was een kabinet opgesteld uit de zeventiende eeuw waarvan de catalogus meldt dat de engelen- en dierenkopjes zijn weggesneden. ${ }^{3}$ Dit voorbeeld sloot aan op de bewustwording van het Nederlandse bestuur en de Europese samenleving in Indië van de aanwezigheid van de islam in de Javaanse cultuur. ${ }^{4}$

In de kap van de rugleuning is een wapen in een ovaal gesneden. Het wapen is zeer waarschijnlijk toe te schrijven aan de predikant Nathanaël de Pape (of Le Pape). ${ }^{5}$ Nederlandse predikanten gingen niet graag naar Indië en De Pape werd dan ook door de Kamer van Zeeland als strafmaatregel naar Indië gezonden. In 1661 had hij een aanstootelijk boekje uitgegeven. ${ }^{6}$ Hij kwam in 1664 in Batavia aan en werd een jaar later naar Negapatnam op de Coromandelkust gezonden. In 1672 werd hij overgeplaatst naar Paleacatte, ook op de Coromandelkust. Acht jaar later keerde hij terug naar Batavia waar hij in 1688 zou overlijden. De Pape heeft in totaal 15 jaar als predikant gewerkt aan de zuidkust van India.

Dit type stoelen wordt gedateerd tussen 1680 en 1720 . Als de stoel aan

De Pape heeft toebehoord dan moet het meubel gemaakt zijn vóór zijn overlijden in 1688. Aannemelijk is dat de armstoel gemaakt is in de periode dat De Pape gestationeerd was op de Coromandelkust, maar de stoel kan ook zijn vervaardigd vlak voor hij naar Batavia terugkeerde. In beide gevallen hebben we te maken met een vroeg voorbeeld van het type.

\section{Een armstoel uit Batavia}

De andere afgebeelde stoel heeft geen inlegwerk van ivoor, maar is in zijn soort wel bijzonder ( $a f b .2$ ). Op basis van het type en het snijwerk in halfreliëf kan worden aangenomen dat deze is vervaardigd in Batavia. Bijzonder aan de armstoel zijn onder andere de onderregels. Bij dit type stoel worden doorgaans getordeerde sporten of een gesneden regel toegepast. Deze stoel heeft een combinatie van deze elementen. Er zijn in verschillende collecties een aantal stoelen en banken bekend met een dergelijke combinatie. ${ }^{7}$

In het boek van Van de Wall uit 1939 over koloniaal meubilair is een foto uit 1919 opgenomen van de eerder genoemde historische tentoonstelling in Batavia. De tentoonstelling werd samengesteld door het Koninklijk Bataviaasch Genootschap van Kunsten en Wetenschappen op basis vaju de 

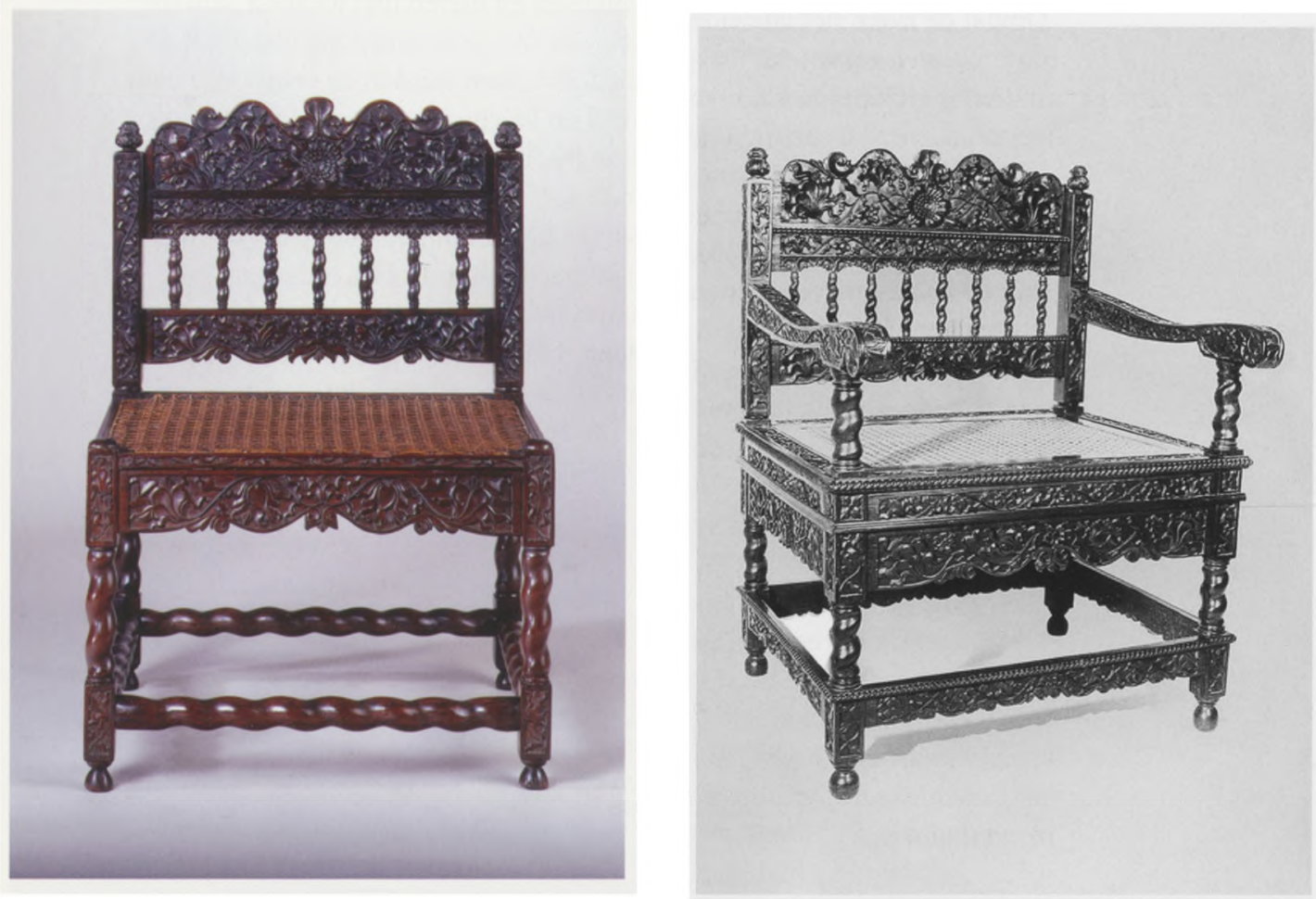

Afbeelding 3 (links) Stoel, kaliatoerhout h. $73 \mathrm{~cm}$.

Batavia of Indonesie, 1680-1720

Cemeentemuseum

Den Haag, legaat

familie Van Hogendorp

Afbeelding 4

Armstoel, ebbenhout Batavia, 1680-1720

Privé verzameling collectie van het genootschap en van particuliere verzamelaars. Op de voorgrond staat een armstoel afgebeeld met de rug naar de beschouwer toe. Deze stoel lijkt identiek te zijn aan de stoel van het Rijksmuseum. ${ }^{8}$ Uit de catalogus die bij de tentoonstelling werd uitgegeven, blijkt dat de collecties van de verschillende verzamelaars bij elkaar geplaatst zijn. Op de foto staan ook nog een ander armstoel, twee lage stoelen, een bank, een grotere bank en een vierkante lage tafel. Dit groepje meubelen komt overeen met de beschrijving van de verzameling van de heer C.A. Wiessing uit Weltevreden en het is waarschijnlijk dat deze armstoel tot zijn verzameling heeft behoord. ${ }^{9}$

\section{Vergelijking met andere stoelen}

In de kap van de rugleuning slingeren ranken en bloemen zich vanuit een centaal geplaatste lotusbloem. Een dergelijke opbouw komt vaker voor, maar de keuze en uitvoering van bloemen, ranken en bladeren verschillen per meubel. Op een kaliatoerhouten stoel die in het bezit is van het Gemeentemuseum Den Haag is een vrijwel identieke kap te zien (afb. 3). ${ }^{10}$ Het snijwerk wijkt alleen af in details. Zo heeft de lotusbloem van de ebbenhouten stoel geribbelde bloembladeren en de stoel van het Gemeentemuseum golvende bloembladeren. Verder zijn de bloemen, bladeren en ranken van de Haagse stoel iets verfijnder uitgewerkt. 
De stoel uit het Gemeentemuseum is niet de enige die sterke overeenkomsten heeft met de ebbenhouten armstoel van het Rijksmuseum. Een andere ebbenhouten armstoel bevindt zich in een particuliere collectie (afb. 4). ${ }^{11}$ Deze stoel heeft op meerdere onderdelen een sterke verwantschap met de stoel van het Rijksmuseum. De armstoel van het museum is echter iets rijker uitgevoerd door het gebruik van halve kabelranden tussen de verschillende onderdelen en de eerder genoemde bijzondere combinatie van de sporten.

De kap van de rugleuning heeft een vrijwel identieke keuze, opbouw en uitvoering van ranken, bladeren en bloemen; ook hier zijn bijvoorbeeld de bloembladeren van de lotus geribbeld. De foto is helaas vrij donker uitgevallen, waardoor de kleinste details niet goed zichtbaar zijn. Ook de twee regels onder de zitting lijken identiek. De stoel uit de particuliere verzameling wordt gedateerd rond 1700 door de vondst van meerdere gekerfde letters die vermoedelijk afkomstig zijn van een schrift dat gebruikt werd in Manipur. Dit schrift werd na 1709 vervangen door het Bengaalse schrift. ${ }^{12}$

Op basis van de overeenkomsten tussen de laatste drie stoelen zou voorzichtig kunnen worden geopperd dat er in de werkplaatsen in Indië mallen of modeltekeningen werden gebruikt. Dat er afwijkingen bestaan in de uitwerking van het snijwerk zou kunnen duiden op de verschillende ambachtslieden die in een werkplaats werkten. Of er werkelijk sprake kan zijn van meubels die toe te schrijven zijn aan een werkplaats zal nader onderzoek moeten uitwijzen.

\section{Noten}

1. J. Veenenedaal, Furniture from Indonesia, Sri Lanka and India during the Dutch period, Delft, 1985, p. 117 en 121.

2. A. Jaffer, Furniture from British India and Ceylon, London, 2001, p. 133.

3. Catalogus van de historische tentoonstelling ter gelegenheid der herdenking van het drie-honderd-jarig bestaan, 30 mei 1919, Weltevreden, 1919, p. 6.

4. In het boek De stille kracht van Louis Couperus komt een hadji (islamitische bedevaartganger) voor die de Europese hoofdpersonen angst inboezemt.

5. Het wapen wijkt echter op twee details af van het wapen dat bekend is van De Pape. De keper van het wapen op de stoel is golvend en is beladen met vijf hermelijnstaartjes, maar het wapen dat de Indische Navorscher (Jrg. 5 (1939), p. 72) afbeeldt heeft dat niet. Door deze afwijkingen is het niet absoluut zeker dat het wapen aan De Pape toebehoorde.

6. C.A.L. Troostenburg de Bruijn, Biographisch Woordenboek van Oost-Indische predikanten, Nijmegen, 1893, p. 529.

7. Onder andere een armstoel uit de Collectie Purba Sutana in Jakarta en een bank uit de collectie van het Museum Nusantara in Delft; Veenendaal, op.cit., p. 48 en 54.

8. V.I. van de Wall, Het Hollandsche Koloniale Barokmeubel, Antwerpen/'s-Gravenhage, 1939, p. 37.

9. Catalogus 1919, op.cit., p. 12.

10. T. Eliëns (red.), Wonen op de Kaap en in Batavia 1602-1795, Zwolle, 2002, p. 69.

11. Veenendaal, op.cit., p. 47.

12. Eliëns, op.cit., p. 33, afb. 16 b. 